\title{
International Assistance Operations in Disaster Situations
}

\author{
Remi Russbach, MD
}

Sound disaster preparedness and a well-organized, local and material response will considerably reduce the necessity for calling on international assistance in the event of disaster. However, despite an excellent level of preparedness, some dramatic situations in the wake of a large-scale disaster always will make the mobilization of international resources absolutely essential.

The international network for disaster relief is quite complex. Many governments have set up emergency relief teams to cope with disasters in their own countries and are able to assign these teams to international relief operations. This type of governmental assistance is provided under agreement with the other governments involved. The United Nations (UN), through the Office of the UN Disaster Relief Coordinator (UNDRO), can play a role in coordinating emergency operations.

Depending on their terms of reference and their size, voluntary agencies also play a very important role in the event of a disaster. Their activities can be coordinated by the government; they can act independently or in concert with local organizations (e.g., churches). Some voluntary organizations are funded by their respective government, others by churches or private donors.

Specifically, the Red Cross and Red Crescent network has a significant role to play in case of a major disaster and the tasks of each of its components in this role is defined precisely. The National Red Cross and Red Crescent Societies, now exist in a combined total of 148 counties and act as auxiliaries to the public authorities in the humanitarian field. These two organizations are involved on a voluntary basis in disaster preparedness and response. The extent of the involvement of each varies from country to country.

When the magnitude of a disaster exceeds the capacity of the national relief services, the national Red Cross or Red Crescent Society can appeal for assistance to its sister societies, either directly or through the League of Red Cross and Red Crescent Societies, This request can be financial, material, and/or in the form of human resources.

In the event of an armed conflict, where a neutral organization is needed, the International Committee of the Red Cross, a private Swiss organization, acts on the basis of the Geneva Conventions, takes charge of relief activities and coordinates Red Cross and Red Crescent relief efforts. In some cases, at the request of the governments involved, this coordination can be extended to include other organizations. The nature, organization, and coordination of such international responses are one of the favorite topics at every meeting on disaster preparedness.

A lot of effort already has been expended by governmental and non-governmental agencies to improve coordination and to make the responses of international relief organizations rapid, appropriate, and efficient. Owing to the large

Chief Medical Officer, International Red Cross, Geneva, Ch 1202, Switzerland

Presented at the 6th WCEDM, Hong Kong, September 9, 1989 
number of organizations willing to participate in relief activities, and owing to logistic, administrative, and political constraints, an ideal situation is hard to reach. However, substantial progress has been achieved in this respect during the last decade. Certain basic principles have been agreed upon by all parties, though they are not always applied. Generally, the need for rapid assessment and for appropriate responses which correspond to the victim's priorities is admitted, but order and discipline among the donors still is very difficult to obtain.

Ideal coordination is extremely elusive. If coordination is very strong and centralized, administration can become overloaded, causing a bottleneck which slows down the relief process. On the other hand, weak coordination can lead to the misuse of resources, duplication, and the sort of unmanageable disorder that has been described as a "secondary disaster."

Relief coordinators and volunteers have to be trained and prepared to play their respective roles while taking into consideration what others are doing and integrating all activities into the general effort.

Relief teams coming from abroad must be professionally trained, able to communicate with the local population, and self-sufficient. Too often, untrained people coming with a lot of good will but no professional skills have disrupted relief operations by mobilizing already overworked local people and have overloaded logistic means for their own purposes, while not being able to produce anything efficiently and appropriate to help meet the priority needs. Each disaster situation is different and a response appropriate to local circumstances has to be found for each specific case. There is no standard solution.

For obvious reasons, when a general disaster strikes, the immediate response only can be local. Owing to the efficiency of the media, relief organizations and governments gener- ally are spurred into action by public opinion before they receive an official request for help and before they obtain precise information from the authorities involved. At the very beginning, given the awareness that people are dying, the temptation is great to act immediately by sending relief before being asked for it. To prevent this reaction, the local authorities immediately must give potential donors some indication as to the actual needs. These estimates must be based on an initial assessment, before any more precise assessment has been carried out. This preliminary information has to be updated regularly and modified, assimilating the results of further evaluation.

It is important to realize that even if the disaster can be managed locally, to refuse international help is a very sensitive matter and may be misunderstood by the donors, who are in direct contact with the victims through the media and are keen to participate in the relief operation. It is up to the donors to supply appropriate items, properly packed, labelled, easy to store (in the case of material relief), and to send well-trained and qualified people when they physically participate in international relief operations.

Unlike natural disaster, armed conflicts are chronic upheavals characterized by a succession of acute and tragic disasters. The breakdown of local structures and security problems make relief activities in armed conflicts very different from those undertaken in the event of natural disaster, although the basic needs may be comparable.

In the event of armed conflict, assistance can be given to victims provided an agreement with one of the parties involved, and that those victims are in a safe place controlled by the party concerned. However, in present-day conflicts, most of the victims are civilians caught in unsafe areas between warring parties, or military victims in the enemy's hands.

In these endeavors to protect the victims of conflict and to provide 
them with assistance, the main problem encountered is access and the risk of seeing relief supplies escape the donors' control and be used for political or military purposes. Access to such victims has to be negotiated on a purely humanitarian basis, with all parties involved in the conflict. The relief operation has to be developed according to the principles of neutrality and impartiality; it must meet the vital needs of the victims and be carefully monitored.

In all major disasters, the needs of the victims and the response to be given have to be considered as part of an overall approach; it is a mistake to consider medical needs as a special entity outside of the general context. Furthermore, the health problems of the victims in the immediate aftermath differ from those that arise later. At the very beginning, the main problems are first aid and evacuation, which have to be initiated immediately by the people on the spot. The next problem relates to the capacity of the medical and surgical system to cope with a large number of casualties. In addition, in every large-scale disaster, we have to face the problem of the displaced population with all the health problems stemming from the lack of essential resources: sufficient and safe water; food, sources of energy; and protection against cold and bad weather. During armed conflicts, this alarming situation is made worse by security problems and human violence against displaced persons. The priorities of the relief operations have to be defined in accordance with the relative importance of these problems, always keeping in mind that resuscitation and medical care are not the only life-saving activities. These can include sanitation programs, water distribution, the building of shelters, and the distribution of sufficient and suitable food.

This multi-disciplinary approach is of the utmost importance and every specialist has to understand his or her role in relation to the complex mechanism of emergency relief operations.

To facilitate international coordination on the ground in emergencies, we have to provide health and relief workers with professional training before they become involved in an emergency situation, so as to give them the best chance of being useful. In various countries, some universities and some relief organizations already have started this kind of training. The International Society of Disaster Medicine currently is preparing a draft curriculum of the different topics which have to be included in any internationally recognized course of training designed to improve the assistance provided to disaster victims.

For the last five years, the ICRC jointly with World Health Organization (WHO) and the University of Geneva Faculty of Medicine, have been organizing a training course for medical coordinators in disaster situations. This one-month course, known as Health Emergencies in Large Populations (HELP) is offered annually. The course covers various topics such as epidemiology, communicable diseases, planning, nutrition, environmental health, war victims protection, disaster response teaching methods, and is designed to prepare future medical coordinators with this multidisciplinary approach.

If all would agree on certain basic principles in relation to international emergency assistance and if the different organizations participating in the international effort were using welltrained people, coordination, which is so difficult to impose today, would be accepted more easily for the benefit of the victims of disaster.

We trust that this 6th World Congress will be a significant step in that direction and will facilitate cooperation and exchange of experience among people involved in alleviating the suffering of disaster victims. 